\title{
ABORDANDO AS REPRESENTAÇÕES SOCIAIS A PARTIR DE EIXOS SIMBÓLICOS
}

\section{Approaching Social Representations from Symbolic Axis}

\author{
Carlos Roberto Santos Vieira \\ Mestre em Administração pela PUCRS \\ $\underline{\text { carlos_robertovieira@terra.com.br }}$ \\ Maria Tereza Flores-Pereira \\ Universidade Federal do Rio Grande do Sul \\ mtfpereira@terra.com.br
}

Marie Anne Macadar Professora do Programa de Pós-Graduação em Administração da Pontifícia Universidade Católica do Rio Grande do Sul marie.macadar@pucrs.br

Submissão: 30/09/2012

Aprovação: 06/08/2012

\section{Resumo}

O objetivo deste artigo é demonstrar como a compreensão das Representações Sociais pode tornar-se mais didática ao ser adotada uma sistemática de análise com o uso de eixos simbólicos. Para isso, este artigo utiliza-se de um estudo de caso que tinha como objetivos identificar e interpretar as Representações Sociais que os clientes de um banco construíam em relação ao atendimento prestado. A partir da análise de informações documentais, da observação participante e, principalmente, de entrevistas com clientes do banco, foi possível identificar nove representações, que foram organizadas e interpretadas a partir de três eixos simbólicos: faixa etária, papeis e funcionários.

Palavras-chave: Representações Sociais; Eixo Simbólicos; Estudo de Caso 


\begin{abstract}
This paper aims to show that social representations can be better understood by means of a systematical analysis of symbolic axis. In order to achieve this goal, a case study is carried out whose main objective is to understand the social representations that bank customers with an extensive relationship with a bank build from the services they get from the institution. The data analysis used documents, participant observation and specially interviews with customers. We have identified nine representations that were organized and interpreted in three symbolic lines: age group, roles and employees.
\end{abstract}

Key words: Social Representations; Symbolic Lines; Study Case 


\section{Introdução}

A teoria das Representações Sociais tem como sua área de conhecimento de origem a Psicologia Social, porém apresenta um grande histórico de utilização na Sociologia e Antropologia, assim como em áreas do conhecimento mais aplicadas como as da Saúde, da Educação e, inclusive, a da Administração. Apesar das nuances de seu uso em cada uma dessas áreas, o uso dos pressupostos epistemológicos e metodológicos da teoria das Representações Sociais vem servindo para que se conheça um tipo de comunicação humana diária, baseada naquilo que seu teórico fundador Serge Moscovici denominou como conhecimento senso comum. Tal comunicação é construída a partir de um repertório coletivo de signos que permite a qualquer indivíduo falar, por exemplo, de uma organização, sem necessariamente esta estar fisicamente presente.

Representar, portanto, é relacionar-se com um objeto, um pensamento, um sentimento, ou consigo mesmo, trazendo para o presente o que está distante. Este processo é uma tradução mental que se inicia com o pensamento do que não está presente e resulta em uma simbolização que é concretizada na linguagem. Para que este fenômeno social funcione, é necessário que os signos utilizados para simbolizar o que está distante sejam comuns entre aqueles que estão representando. É preciso, portanto, que as ideias sejam socializadas e façam sentido coletivo em um determinado contexto. Conhecer as Representações Sociais de um determinado grupo social significa, então, compreender o simbolismo que (des)ordena os pensamentos, as interpretações e, inclusive, as ações do "outro".

Por esta possibilidade de se conhecer em profundidade tal comunicação humana coletiva e cotidiana, a teoria das Representações Sociais vem sendo utilizada nessas mais diversas áreas do conhecimento. No campo da Administração, mais especificamente, tal teoria abre amplo espectro de possibilidades de conhecer, por exemplo, o trabalho, a gestão, o consumo a partir dos próprios atores que atuam nessas atividades. Descobrir como estes atores representam um determinado objeto - um processo de trabalho, um procedimento administrativo, uma determinada marca, por exemplo - pode ser um conhecimento de grande valia para um trabalhador, para um gestor e até mesmo para um consumidor, pois conhecer os modos como as pessoas representam determinado fato da sociedade - ou, no caso em questão, das organizações - abre caminho para que esses atores posicionem-se a respeito de si mesmo - ou do "outro" - e percebam melhor o seu papel em um contexto mais amplo (MARKOVÁ, 2006). 
O presente artigo parte de uma pesquisa que visava primordialmente identificar e interpretar as Representações Sociais de clientes de um banco estadual brasileiro, o Banrisul. Porém, mais do que apresentar as representações identificadas e suas respectivas interpretações, neste artigo será discutida uma sistemática de análise destas representações a partir daquilo que aqui se denomina como eixos simbólicos. Pretende-se com esta discussão auxiliar outros pesquisadores a encontrar maneiras mais didáticas de realizar suas análises e apresentar suas interpretações acerca das Representações Sociais. Para preparar o leitor nesse sentido, construiu-se o presente artigo a partir de quatro seções além desta introdução: o referencial teórico, o método, a análise, e, finalmente, as conclusões. 


\section{Referencial Teórico}

As contribuições teóricas de Serge Moscovici, baseadas principalmente em Durkheim (teoria das representações coletivas) e Piaget (teoria de desenvolvimento); foram fundamentais para a formação do que é conhecida hoje a teoria das Representações Sociais. Publicado em 1976, o estudo sobre as Representações Sociais da Psicanálise na sociedade parisiense chamado $L a$ psychanalyse, son image, son public foi considerada a obra seminal da mais contemporânea teoria das Representações Sociais e até hoje é citada, na maioria dos estudos consultados, como pedra fundamental do tema (FARR, 1995).

Nesse contexto, a teoria das Representações Sociais se funda como um empreendimento interdisciplinar (GUARESCHI, 2011, p. 17), pois se encontra entre o individual da psicologia e o coletivo da sociologia, uma vez que a centralidade da discussão não fica no "puro objeto" ou "puro sujeito", mas na inter-relação desses.

Não é acidental, portanto, que uma das bases mais fortes que a teoria das Representações Sociais vai buscar na psicologia está na obra piagetiana. Mas, se a atividade do sujeito é central para a teoria, não menos central é a realidade do mundo. O fato de Moscovici permitir-se olhar para a Sociologia [Durkheim], lá encontrar conceitos, e ousar trazê-los para o domínio da Psicologia Social é revelador do papel central que o mundo social ocupa nas Representações Sociais. (GUARESCHI, 2011, p. 19).

A teoria das Representações Sociais, portanto, oferece um arcabouço conceitual amplo (intermediando questões psicológicas e sócio-culturais) que permite acessar as representações - ação social mental, manifestada através da linguagem - e as práticas sociais que as pessoas (re)constroem e executam quando constituem sua relação com a sociedade e o "outro". No entendimento desta teoria, a realidade é vivida e também representada através dos atores sociais que se movem, constroem a vida e explicam-na mediante seu estoque de conhecimento.

O senso comum é o campo prioritário das Representações Sociais e por isso elas são sempre complexas e necessariamente estão inscritas dentro de um referencial, de um pensamento já preexistente. Entre o senso comum e as Representações Sociais está a elaboração das pessoas sobre os fatos e principalmente o discurso pelo qual se chega à coerência argumentativa, a um status simbólico que estabelece um vínculo entre o individual e o coletivo. Além disso, Representações Sociais são complexas e fluem em direção a um núcleo semântico que tem uma origem determinada. Neste cenário complexo de interação social, as Representações Sociais têm duas funções: a ancoragem e a objetivação. 
A ancoragem se refere ao mecanismo pelo qual se busca transformar algo estranho em familiar e integrá-lo ao conhecimento preexistente. O que é desconhecido é reajustado para que se enquadre em uma categoria já conhecida. A função da ancoragem é facilitar a interpretação de características, a compreensão de intenções e motivos subjacentes às ações das pessoas e formar opiniões (MOSCOVICI apud SOUZA et al., 2010). Já a objetivação é a forma de transformar o que é abstrato e novo em imagem concreta, apoiado em concepções familiares. Já a objetivação é tornar algo temático, relevante a sua consciência, os indivíduos o transformam ao mesmo tempo em um objeto para eles próprios ou, mais precisamente, em um objeto pertencente a uma realidade escolhida entre todas as outras realidades possíveis ou anteriores.

No campo da Administração, apesar do material produzido ser mais recente, já se encontram publicações acadêmicas sobre o tema. Um levantamento no site de busca de artigos científicos Scielo (com as palavras-chave Administração e Representações Sociais), complementado por uma detalhada pesquisa (com a expressão Representações Sociais) em oito revistas brasileiras tradicionais da área da Administração - Cadernos EBAPE, Organização e Sociedade (O\&S), Revista de Administração Contemporânea (RAC), Revista de Administração de Empresas (RAE), Revista de Administração Mackenzie (RAM), Revista de Administração da USP (RAUSP), Revista de Administração Pública (RAP), Revista Eletrônica de Administração (REAd) - apresentou como resultado dezoito artigos publicados entre os anos de 2002 a 2012. Tal quantidade e o fato de ser uma produção bastante recente demonstra a vivacidade do uso de tal teoria no campo da Administração.

É possível notar que nestes artigos se apresentam quatro linhas de uso da teoria das Representações Sociais: o conhecimento de símbolos e significados, as práticas organizacionais decorrentes das representações elaboradas, a análise da cultura organizacional e a investigação de funções identitárias, neste caso, predominantemente de gênero. O quadro 1 apresenta os resultados deste levantamento e da organização destes artigos a partir de quatro linhas de estudo das Representações Sociais.

Mesmo apresentando usos diferentes da teoria das Representações Sociais para a compreensão das organizações e do trabalho, tais artigos se assemelham na forma de apresentar seus resultados, no caso, as Representações Sociais que foram foco de estudo são analisadas individualmente e são contextualizadas pelos referenciais teóricos e pelos dados coletados. O presente artigo propõe uma forma diferente de análise das Representações 
Sociais: uma que também organize as representações a partir de eixos simbólicos visando contribuir para uma compreensão mais didática e ampliada das próprias das representações em análise. 
Quadro 1 - Linhas de Estudo em Representações Sociais em Administração.

\begin{tabular}{|c|c|c|}
\hline $\begin{array}{l}\text { Linhas de Estudo em } \\
\text { RS e Administração }\end{array}$ & Trabalhos de Referência & Abordagem \\
\hline \multirow{6}{*}{$\begin{array}{l}\text { Interpretação de } \\
\text { Significados }\end{array}$} & Fleig et al. (2005) & Interpretação dos significados do desemprego \\
\hline & Corrêa (2006) & Relações de símbolos e significados em contexto organizacional (cultura organizacional) \\
\hline & Waiandt; Davel (2008) & Representações emergentes da organização em fase de sucessão - símbolos e significados \\
\hline & Souza; Serafim; Dias (2010) & Diferenças de significação entre grupos na organização e representações do papel de gestor \\
\hline & Borges;Medeiros; Casado (2011) & $\begin{array}{l}\text { Representações de estudantes em situações na qual a ética e a competitividade estão presentes de } \\
\text { forma paradoxal }\end{array}$ \\
\hline & Lescura et al. (2012) & Representações acerca do parentesco em organizações familiares \\
\hline \multirow{3}{*}{$\begin{array}{l}\text { Estratégia } \\
\text { Organizacional }\end{array}$} & Cavedon; Ferraz (2005) & Representações presentes nas práticas de gestão de pequenos comércios \\
\hline & Tomaselli; Oltramari (2007) & Universo reificado e pensamento consensual na tomada de decisão \\
\hline & Carrieri; Silva; Junquilho (2008) & Representações a respeito da estratégia na prática \\
\hline Cultura Organizacional & Fantiel;Cavedon (2009) & Compreensão das dimensões simbólicas de cultura organizacional, por meio das representações. \\
\hline \multirow{3}{*}{ Função identitária } & Cramer; Paula Neto; Silva (2002) & Função identitária das Representações Sociais \\
\hline & Melo et al. (2004) & Análise das representações femininas em periódicos sobre negócios \\
\hline & Andrade et al. (2007) & Representações sobre a questão de gênero e função identitária \\
\hline
\end{tabular}

Fonte: O autor (2012). 


\section{Metodologia}

\subsection{A Forma de Acessar o Conhecimento}

A pesquisa empírica que serviu como base para análises deste artigo está alinhada a uma abordagem qualitativa de cunho interpretativo. Segundo Prasad e Prasad (2002), estes termos não podem ser entendidos como sinônimos, e diversas características de uma e de outra abordagem devem ser consideradas para fazer esta necessária distinção. Para tais autores, a abordagem interpretativa é um domínio da pesquisa qualitativa, mas nem toda pesquisa qualitativa é interpretativa, tendo em vista que em muitos casos as primeiras não estão alinhadas com a essência do interpretativismo. Ou seja, como destaca Sandberg (2005), os pressupostos ontológicos e epistemológicos são extremamente distintos entre a tradição positivista e a interpretativa de pesquisa. Assim, o método qualitativo de pesquisa baseia-se na conjunção de diversas perspectivas filosóficas, variadas técnicas de pesquisa, procedimentos metodológicos e diferentes formas de apresentação. Prasad e Prasad (2002) caracterizam a pesquisa qualitativa como uma possibilidade do positivismo, e todos os consequentes desdobramentos desta forma, de abordar a realidade. Por outro lado, Sandberg (2005) ao identificar uma grande variedade de enfoques no desenvolvimento da pesquisa interpretativa (teoria crítica, construcionismo social, interacionismo simbólico entre outros), destaca que a base fenomenológica é ponto de unificação entre esta diversidade.

A pesquisa organizacional interpretativa se distingue da qualitativa positivista tendo em vista que para o entendimento dos novos paradigmas sociais é necessário estender as fronteiras da pesquisa positivista. Na prática este posicionamento implica em algumas questões importantes. Primeiramente, é fundamental destacar que o interpretativismo tem compromisso com uma filosofia mais ampla de entendimento do mundo como uma construção social e que o objetivo desta abordagem não é captar uma realidade pré-existente e sim o simbolismo de um mundo em constante ressignificação. Particularmente no campo da Administração, esse tipo de pesquisa se preocupa com os significados locais das questões ligadas a esta área de conhecimento e com os simbolismos do cotidiano das organizações. Sendo assim, são privilegiadas as micro realidades, as abordagens individuais de cada empresa (e de seus atores) e suas particularidades em detrimento de generalizar os contextos de muitas organizações simultaneamente (PRASAD e PRASAD, 2002). 
Por sua vez Patton (2002) justifica que os estudos interpretativos estão mais “...interessados em compreender em profundidade um caso específico, dentro de um determinado contexto, do que buscar hipóteses generalizáveis" (p. 267). Contudo, severas críticas são levantadas pelos defensores dos estudos positivistas quanto a falta de generalização em estudos de caso interpretativos (método normalmente adotado pelos estudos interpretativos). Lee e Baskerville (2003) apresentam um modelo de generalização com quatro componentes: dos dados para a descrição; da descrição para a teoria; da teoria para a descrição e de conceitos para teoria.

Nessa mesma linha, diversos autores tem demonstrado preocupação no estabelecimento de critérios que assegurem a qualidade das pesquisas interpretativas (SANDBERG, 2005; WALSHAM, 2006; PATTON, 2002). Walsham (2006), cita os trabalhos de Golden-Biddle e Locke (1993) que apresentam três critérios: autenticidade, plausabilidade e criticidade. De forma mais detalhada, Klein e Myers (1999) criaram, com base em estudos advindos de diversas áreas sociais, sete critérios (ou princípios) que justificam o enfoque interpretativo em estudos de caso. Buscando atingir critérios de generalização trabalhado por estes autores, buscou-se a reflexão teórica em cima do caso de estudo, o que resultou nos Eixos Simbólicos apresentados na próxima seção.

\subsection{Estratégia de Pesquisa e Coleta de Dados}

Conforme Walsham (1995), o estudo de caso em profundidade é meio usualmente utilizado na pesquisa interpretativa. Nele o pesquisador se envolve em frequentes visitas ao campo durante longos períodos de tempo (p.74). A principal fonte de evidência, conforme este autor, são as entrevistas em profundidade com base em roteiro semiestruturado. Esta foi uma das forma de coletas de dado da presente pesquisa. Contudo, dentre as alternativas disponíveis para a coleta de dados qualitativos, as que mais auxiliaram no atingimento dos objetivos da pesquisa sobre as representações dos clientes do Banrisul foram a documental direta e indireta, a observação participante e as entrevistas. O principal motivo desta escolha relacionou-se com a natureza das Representações Sociais que têm a palavra (falada e escrita), como vetor principal de acesso aos fatos representados. No entanto, é importante destacar que as entrevistas foram ainda mais predominantes na pesquisa em questão, tendo em vista que proporcionou acesso direto ao discurso dos clientes do banco Banrisul, logo às representações elaboradas. A análise documental - fontes secundárias de pesquisa como livros publicados sobre o Banrisul, conteúdos do site do banco na internet e publicações gerais sobre a instituição que são de domínio públicos - somente ilustrou eventuais ancoragens ou 
objetivações, serviu de confirmação e instrumento de apoio e ilustração das entrevistas, não se constituindo elemento determinante para a realização das análises das Representações Sociais.

A observação científica segundo Angrosino (2009) é o ato de perceber um fenômeno e registrá-lo com propósitos científicos. Mas observar, em um primeiro entendimento, pode remeter à imagem de um sujeito exterior ao fenômeno pesquisado, se envolvendo minimamente na dinâmica dos atores envolvidos. No entanto, acompanhando as especificidades de cada pesquisa, é possível encontrar estudiosos que têm toda uma proximidade com o objeto pesquisado, quase até se confundindo como "nativo" na comunidade onde atua. Neste sentido, o autor conceitua que o termo participante é uma combinação do papel do pesquisador (participante de algum modo) e uma técnica real de coleta de dados (observação), além disso, o autor também esclarece que este não é um método de pesquisa e sim uma estratégia para trabalhar em campo.

As reuniões que foram foco da observação participante ocorreram durante os meses de janeiro a junho de 2011 e sempre tiveram como pauta a elaboração de estratégias comerciais do Banrisul. As anotações foram feitas em diversos relatórios de reunião que foram consultados durante a análise dos dados. A postura do pesquisador durante a reunião foi sempre de participação como funcionário do banco, dando contribuições à discussão e tendo um comportamento ativo como debatedor de ideias e proponente de soluções. Conforme Walsham (2006) este é o tipo de observação desejada em estudos interpretativos, apesar do alto tempo dispendido no envolvimento dessa forma de coleta de dados.

As entrevistas foram realizadas entre os meses de março e maio de 2011 com 10 clientes do Banrisul entre as relações pessoais dos pesquisadores e por indicação dos próprios entrevistados. As pessoas entrevistadas foram selecionadas pelos seguintes critérios: (i) ser funcionário público ativo ou aposentado e (ii) ter uma relação extensa com o Banrisul. Por relação extensa entende-se ter pelo menos uma conta corrente em movimento há no mínimo dez (10) anos no Banco em questão. Dos entrevistados quatro são do sexo masculino e seis do feminino. As idades variaram de 29 a 69 anos, residentes no interior e na capital gaúcha.

Do conjunto das entrevistas e das anotações realizadas a partir das observações participantes foi possível obter algumas Representações Sociais. Para tal, foi realizada análise dos dados de forma manual, na qual os dados semelhantes ou divergentes eram agrupados por categorias e em seguida interpretados e inter-relacionados. 
Na próxima seção é apresentada a análise e demonstrado como os eixos simbólicos surgiram com base no estudo de caso realizado. 


\section{Análise}

\subsection{O Caso: Banrisul, o Banco do Estado do Rio Grande do Sul}

\subsection{Análise, Fase I: As Representações Sociais do Atendimento do Banrisul}

O primeiro movimento de análise do material empírico obtido a partir dos documentos, da observação e das entrevistas da pesquisa em questão seguiu uma abordagem tradicional de acessar as Representações Sociais, ou seja, conhecer as simbologias manifestadas através da linguagem (falada ou escrita) que demonstrassem um vínculo entre o individual e o coletivo. Tal vínculo foi percebido no processo de análise à medida que a linguagem utilizada flui em direção a um mesmo núcleo semântico demonstrando, assim, algumas unidades de pensamento (mesmo que temporárias) entre diferentes atores sociais (por exemplo, os atores que escreveram os documentos, os atores que participaram das entrevistas). Tais núcleos semânticos, que se referem às próprias representações sobre os fatos sociais, são naturalizadas pelas pessoas e grupos, mas estão muito longe de serem elaborações naturais, pois apresentam uma origem sociocultural específica. Nesse sentido, o estudo das Representações Sociais apresenta pelo menos dois esforços dos seus pesquisadores que se refere: (1) conhecer quais são as representações daquele grupo diante de um fato social (a partir da busca de núcleos semânticos); (2) realizar a interpretação da origem social, cultural e histórica de tais representações.

Foi nesse sentido que os primeiros esforços de análise do material empírico da pesquisa das Representações Sociais em relação ao Banrisul e seu atendimento. A partir da busca de núcleos semânticos e de um refinamento destes, foram encontrados um total nove Representações Sociais principais, sendo que uma delas necessitou de uma divisão temática para fins de uma melhor compreensão de sua totalidade. Quase que simultaneamente a esta definição, foi realizada a interpretação desses núcleos semânticos - as representações utilizando para isso todas as informações empíricas que levavam a esta compreensão (principalmente o uso de falas dos entrevistados), assim como o uso de referencial teórico principalmente das áreas sociais e humanas no sentido de buscar compreender a(s) origem(s) social, cultural e histórica de tais representações. Como o principal objetivo deste artigo se refere à discussão das Representações Sociais que se constroem acerca do fato social 'Banrisul e seu atendimento' nesta parte do trabalho será apresentado um resumo destas, o suficiente para compreendermos a posterior análise das representações a partir de eixos 
simbólicos. Não serão apresentadas, portanto, a análise da(s) origem(s) sócio-históricocultural de cada uma dessas representações.

\subsubsection{Banco e Dinheiro como Brincadeira e Aprendizagem}

Esta representação veio em resposta a uma questão inicial: Qual é sua primeira lembrança sobre bancos e o que significava o banco para você nesta época? As respostas remeteram a questões de infância destacando-se nessa relação - criança e banco - os temas da brincadeira e da aprendizagem. Por exemplo, um grupo de entrevistados rememorou questões ligadas a cofres para guardar moedas que possuíam formas lúdicas, como formigas e porcos de brinquedo. Outros entrevistados referiram a visita à agência bancária como acompanhantes dos pais quando estes precisavam sacar, depositar valores ou fazer operações como retiradas de talão de cheques, aplicações ou empréstimos. Também foi frequente no discurso dos entrevistados a ação de brincar de banco (assumir a função de bancário ou até mesmo de banqueiro) e de brincar com dinheiro. Além da questão da infância, todas essas respostas demonstram um momento no qual brinquedo, brincadeira e aprendizagem estão interligados.

\subsubsection{Banco e Dinheiro como Responsabilidade}

Dando continuidade ao processo de entrevista com a pergunta - Como você começou a se relacionar pessoalmente com bancos? - começa a aparecer a representação de que banco e dinheiro se referem a uma responsabilidade. As respostas remeteram ao início da vida adulta, aquilo que se dos entrevistados, na qual a vida infantil se afastava (brinquedos e brincadeiras) e a responsabilidade de auxiliar a família se iniciava (no caso, fazer o serviço de banco). Nesta representação alguns entrevistados ancoraram também a questão do recebimento dos primeiros salários ou de bolsas estudantis como a entrada na vida adulta e todos os desdobramentos subsequentes, como controle financeiro e possibilidades de consumir produtos bancários, como empréstimo e cadernetas de poupança. Esta fase híbrida, localizada entre somente ir ao banco como acompanhante e ter efetivamente responsabilidade sobre o dinheiro, foi citada por parte dos entrevistados como um aprendizado mais efetivo, um preâmbulo para as responsabilidades da vida adulta.

\subsubsection{O Banco como Instrumento para Operacionalização do Cotidiano}

Esta representação apareceu tanto a partir da questão mencionada na representação anterior, mas também se liga à terceira pergunta do roteiro: Como era o atendimento quando você começou a ter conta em bancos? Tal representação está diretamente ligada à relação que os 
entrevistados constituíam com os bancos já na sua vida adulta, sendo este considerado como um instrumento para a operacionalização de seus cotidianos. Nesse contexto aparece a necessidade de ser atendido pelo caixa executivo (principalmente os entrevistados mais velhos), de ir ao caixa eletrônico (principalmente os entrevistados mais novos), ou, ainda, de ter a necessidade de abrir uma conta bancária para recebimento de seus salários.

\subsubsection{O Banco como Agente Pedagógico}

Uma das questões que derivaram durante o processo de entrevista foi o que significava para os entrevistados o bom atendimento em um banco. As respostas, que até poderiam variar em função das dimensões amplas dos temas abordados, revelaram uma representação quase uníssona: o bom atendimento de um banco é aquele que ensina o cliente. Isso pôde ser percebido no uso frequente da expressão "explicação das coisas", no sentido de ensinar ou educar os clientes acerca do consumo dos produtos bancários que, por vezes, não é simples ou não é bem explicado pelas instituições bancárias. Desta forma, alguns entrevistados relataram que é preciso que o atendimento do banco tenha um espírito pedagógico, ou seja, que ensine o cliente a escolher a melhor alternativa para a equalização de questões financeiras. Desta forma, a representação social que emerge destes discursos diz respeito ao banco como agente pedagógico diferente da escola ou da família. Diz respeito ao banco como entidade de ensino sobre a sua própria missão que é o serviço financeiro.

\subsubsection{O Banco como Parte da Família}

Durante as entrevistas foi muito frequente a referência de haver pelo menos um membro da família exercendo atividade bancária - "Ah eu tenho um filho no Banrisul" e "Meu irmão foi gerente do Banco do Brasil durante anos" - ou ainda dos próprios entrevistados terem sido bancários do Banrisul e de outras instituições - "Eu já trabalhei no Banrisul" e "Eu já fui funcionário do Sul Brasileiro" i”. Estas citações eram feitas em momentos nos quais os entrevistados expressavam que possuíam uma relação estreita (quase familiar) com a organização bancária. Nesta referência também podem estar presentes às questões ligadas ao status social de ser bancário ou de ter um parente trabalhando no setor financeiro, tais questões foram melhor exploradas na representação 'o status de ser funcionário do Banrisul e de outros bancos'. 


\subsubsection{O Banco e seu Atendimento}

As perguntas sobre atendimento - Como era o atendimento quando você começou a ter conta em bancos? Para você, como é o atendimento dos bancos? De uma forma geral, o que você pensa a respeito do atendimento do Banrisul? - geraram uma maioria de respostas sobre o mau atendimento bancário, inclusive do Banrisul. Os depoimentos focaram-se principalmente na demora da fila e na falta de cordialidade dos atendentes. Sobre as filas, os entrevistados relataram sentirem-se desconfortáveis enquanto esperam sua vez de serem atendidos. Quando questionados sobre o porquê deste mal estar, a maioria dos respondentes relatou sentir-se perdendo tempo. Quanto aos atributos esperados dos atendentes, quando perguntados sobre os sentimentos que emergiam quando algum funcionário do banco se mostrava inapto ao atendimento por questões de humor ou inabilidade para lidar com o público, os entrevistados relataram que se sentiam desprestigiados.

\subsubsection{O Funcionário do Banrisul como Figura de Autoridade}

Durante o processo de entrevista, foi possível perceber que para alguns respondentes os funcionários dos bancos podem ocupar no imaginário das pessoas papéis de autoridades, principalmente aquela ligada à racionalidade do sistema financeiro e suas regras muito bem definidas. Durante o relato de um dos entrevistados sobre a sua brincadeira de ser bancário percebeu-se, segundo o conteúdo implícito do discurso (gestos e impostação de voz), que a criança que representava o dono do banco era figura de poder, o que pode aludir que os empregados do banco, especialmente aqueles ligados à gestão, representam fortemente as questões de mando e autoridade. Além de questões da racionalidade do setor financeiro, apareceu nos relatos o fato bastante prático de que a figura do agente bancário está ligada àquele que tem a possibilidade de liberar (ou não) créditos, como empréstimos às pessoas físicas e jurídicas, além de ter a tarefa de manter estas operações adimplentes também. Nesse contexto também apresentou-se uma representação dos funcionários de bancos ligada à figura de autoridade formal, como entes de solução (aquisição de empréstimo) e ao mesmo tempo de temor (fiscalizador das dívidas).

\subsubsection{O Status de ser Funcionário do Banrisul e de outros Bancos}

Foi possível encontrar também nos discursos dos entrevistados uma referência à valorização social de ser funcionário de banco. Esta ideia foi reforçada pela projeção realizada por alguns entrevistados quanto à postura dos empregados bancários que foram retratados como 
possuidores deste status social e alguma soberba. Analisa-se que este tipo de trabalho que não envolve atividade manual e física e, ainda, que é simbolizado por figuras de poder - melhor trabalhadas na representação 'funcionário do Banrisul como figura de autoridade' - traz em si a possibilidade de determinar às pessoas das quais se fala um status positivo e uma posição social desejável e adequada a determinados padrões sociais exigidos para os integrantes da classe média brasileira.

\subsubsection{O Funcionário do Banrisul como Professor}

A partir das entrevistas foi possível elaborar a representação social que estabelece a figura do bancário como professor e o banco como um ente educacional. Esta representação liga-se com a anteriormente apresentada do banco como um agente pedagógico - o banco como lugar de aprendizado, onde é possível "explicar" o funcionamento de produtos e serviços financeiros e orientar o cliente sobre o melhor caminho a ser seguido, em determinada situação - porém, vincula-se à figura do funcionários, mais especificamente. No lugar do professor, os funcionários públicos entrevistados encaixaram a figura do gerente que é a pessoa que efetivamente explica o que é duvidoso, esclarece e indica alternativas viáveis de resolução de questões financeiras. No lugar do aprendente, está o cliente do banco que espera e valoriza aquele funcionário (ensinante) que, por meio da simpatia e da cordialidade, é capaz de construir conhecimento junto a ele.

\subsection{Análise, Fase II: Os Eixos Simbólicos}

Durante a realização dos movimentos tradicionais de análise do material empírico em busca da identificação e interpretação das Representações Sociais acerca do atendimento do banco Banrisul - (1) conhecer as representações a partir da busca de núcleos semânticos; e (2) realizar a interpretação da origem social, cultural e histórica de tais representações começou-se a perceber a possibilidade de se construir uma maneira complementar de organizar, analisar e, portanto, apresentar as Representações Sociais que estavam sendo levantadas, quer seja: os eixos simbólicos. A ideia da constituição de tais eixos surgiu da percepção de havia conexão temática entre algumas Representações Sociais.

Por exemplo, ao realizar a análise mais profunda das representações de banco e dinheiro como brincadeira e aprendizagem, como responsabilidade e, ainda, de banco como operacionalização do cotidiano, começou-se se a perceber que o material teórico (sociológicoantropológico) que passou a ser pesquisado no sentido de realizar a interpretação dessas 
representações remetiam a questões de fases de vida (faixas etárias). A representação de banco e dinheiro como brincadeira e aprendizagem, por exemplo, remeteu a questões de infância dos entrevistados não apenas por que estes se lembravam especificamente desta fase de sua vida, mas também por que brinquedo, brincadeira e aprendizagem se referem a "objetos" culturais vinculado a uma fase de vida que, a partir de um determinado tempo e em determinados lugares, se convencionou chamar de infância. Já a representação de banco e dinheiro como responsabilidade se referia a uma fase na qual os entrevistados começam a "deixar a brincadeira" e dão início a uma fase de responsabilidades à medida que passam a ajudar a família na execução de tarefas "de adultos" como a realização do serviço de bancos, ou até mesmo o recebimento de dinheiro (a partir de trabalho ou bolsas) por conta própria. Convencionou-se chamar esta fase de vida, ao menos em um contexto Ocidental contemporâneo, de adolescência. Por fim, a representação denominada como instrumento para operacionalização do cotidiano esteve muito ligada às relações bancárias que esses entrevistados constituíram em sua vida adulta fase na qual a vivência com as instituições sociais se intensifica (sociedades contemporâneas complexas), com a inserção no mundo do trabalho e a (quase sempre) necessária entrada no mercado bancário.

Já as representações o banco como agente pedagógico, como parte da família e o banco e seu atendimento pareceu também compreenderem juntos uma mesma temática, ou seja, as representações dos papéis de uma instituição bancária, na visão dos entrevistados. O banco como agente pedagógico, por exemplo, apareceu como um importante papel social dos bancos que pode ser pensado para os mais diferentes tipos de usuários, ou seja, desde um cliente já ativo no uso de seus produtos e serviços, mas também pode se estender a uma população excluída dessa forma de instituição social, mas que se pretende que seja inserida. $\mathrm{O}$ banco como parte da família é uma representação de papel do banco pouco esperada, afinal qual é a princípio a relação entre banco e família? É um tipo de representação de papel do banco que pode estar associada a um contexto brasileiro muito específico no qual dinheiro (e por contrapartida as instituições que tem este como objeto central de seu trabalho) tem uma conotação negativa (OLIVEN, 2001). Nesse sentido a família, e seu caráter de positividade na cultura brasileira, pode ser um dispositivo de intermediação entre o usuário e tal instituição social. O banco e seu atendimento já é um papel mais tradicional e esperado em relação a uma instituição que apresenta uma relação intensa com seus clientes. Em tal papel, conforme visto anteriormente, apareceu de maneira mais forte a compreensão negativa do atendimento, seja pela demora nas filas (perda de tempo) ou pela inabilidade e antipatia dos funcionários. 
Um terceiro eixo simbólico pareceu adequado de ser organizado ao passo que outras três representações - o funcionário do banco como figura de autoridade, o status de ser funcionário de banco, o funcionário de banco como um professor - pareciam se unir no que se refere ao seu objeto de representação, no caso, os funcionários bancários. Interessante observar que este eixo simbólico se relaciona de maneira mais clara com outras representações e eixos. Por exemplo, o funcionário como figura de autoridade apareceu nas memórias de criança dos entrevistados (eixo das fases de vida), o status de ser funcionário em alguns momentos apareceu também na representação de banco como parte da família (eixo dos papéis) e, por fim, o funcionário como um professor está ligada à representação de banco como agente pedagógico (também eixo dos papeis). Seja visto como autoridade (poder), como alguém com status (superioridade social) ou como um professor (ligado a questões pedagógicas) o interessante é que a figura do funcionário bancário ocupa um espaço importante nas representações dos entrevistados, no que se refere à sua relação com os bancos. 


\section{Conclusões}

Possivelmente por seu potencial de proporcionar um conhecimento profundo da comunicação humana coletiva e cotidiana, a teoria das Representações Sociais vem sendo utilizada em diversas áreas do conhecimento, e também na área da Administração. Nesta área, especificamente, o uso de tal teoria tem ocorrido no sentido de se conhecer as práticas organizacionais decorrentes das representações elaboradas, a cultura organizacional, questões de identidade nos organizações e no trabalho (predominantemente questões de gênero); como demonstra a produção acadêmico-científica brasileira da área.

De uma maneira geral, o estudo das Representações Sociais se realiza a partir de dois níveis de análise: (1) conhecer as representações de um determinado grupo diante de um fato social a partir da busca de núcleos semânticos; e (2) realizar a interpretação da origem social, cultural e histórica de tais representações. Contudo, durante a análise do material empírico da pesquisa que serviu de base ao presente artigo - as Representações Sociais que os funcionários públicos com extensa relação com o Banrisul constroem com relação à instituição -, percebeu-se a possibilidade de se constituir um terceiro nível de análise das Representações Sociais: (3) organizar as Representações Sociais a partir de eixos simbólicos.

Nesse sentido, as nove Representações Sociais levantadas no processo de análise da pesquisa de base puderam ser sistematizadas em três eixos simbólicos, conforme esquematiza a Figura 1. 
Figura 1 - Eixos simbólicos e as Representações Sociais sobre o atendimento do Banrisul

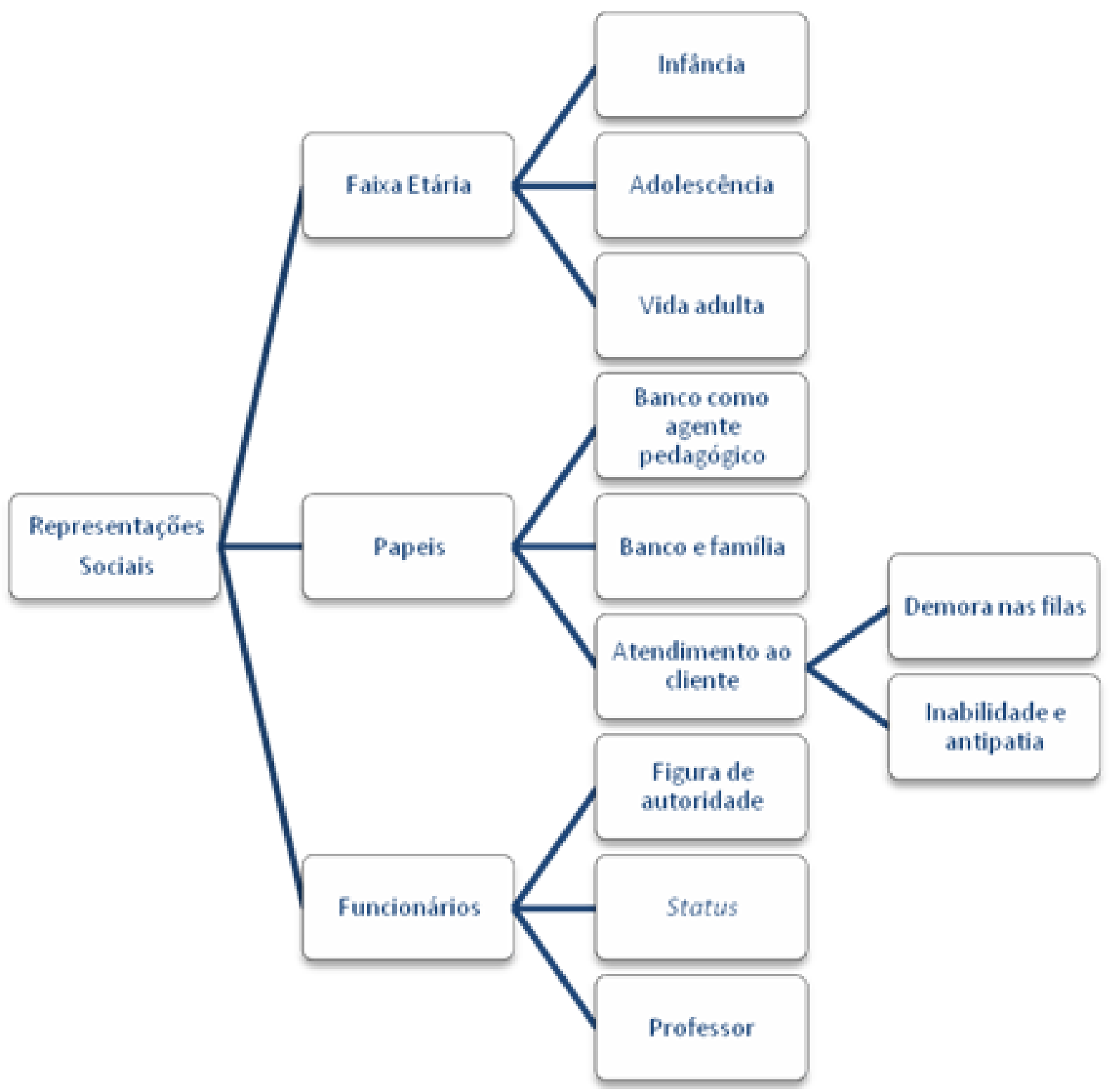

Fonte: $\mathrm{O}$ autor (2012).

O presente artigo compreende que tais eixos funcionam como um instrumento didático de análise e apresentação das Representações Sociais, uma vez que vão além da tarefa de enumerar em um texto cada uma das representações e suas respectivas interpretações sóciohistórica-culturais. Tal modo de organização ajuda a visualizar as conexões entre as Representações Sociais e, assim, pode alavancar ganhos interpretativos e teóricos nos 
resultados de pesquisa. No que se refere aos leitores de um texto sobre as Representações Sociais de um determinado fato social, o uso de tais eixos tenderá a facilitar a compreensão da análise que os pesquisadores realizaram, pois além de uma leitura individualizada das Representações Sociais o leitor terá à sua disposição uma primeira leitura de conexões das Representações Sociais (temáticas, objetos de representação).

O uso de uma figura (ver Figura 1) é ainda uma maneira complementar de apresentar os eixos simbólicos e suas respectivas representações. A ideia é facilitar o fechamento das análises por pesquisadores da área, assim como apresentar uma sistematização visual aos leitores. Acredita-se que esta forma de análise - eixos simbólicos e sua respectiva representação na forma de uma figura - é um novo elemento de análise no estudo das Representações Sociais, especialmente na área dos estudos organizacionais.

\footnotetext{
${ }^{\mathrm{i}}$ O Banco Sulbrasileiro foi uma instituição financeira regional originada em 1973 da fusão dos três maiores bancos gaúchos da época: o Banco da Província do Rio Grande do Sul, o Banco Nacional do Comércio e o Banco Industrial e Comercial do Sul. Em 1985 o Sulbrasileiro sofreu intervenção extrajudicial por falta de liquidez e foi incorporado pelo então Banco Meridional.
} 


\section{Referências}

ANDRADE, Áurea Lúcia Silva; CAPELLE, Mônica Carvalho Alves; BRITO, Mozar José de; PAULA NETO, Alcielis de; VILAS BOAS, Luiz Henrique de Barros. Gênero nas Organizações: um Estudo no Setor Bancário. Revista de Administração de Empresas (RAE), v.1, n.2, Julho-Dezembro 2002.

ANGROSINO, Michael. Etnografia e Observação Participante. Porto Alegre: Bookman, 2009.

BORGES, Jacquelaine Florindo; MEDEIROS, Cintia Rodrigues de Oliveira; CASADO, Tania. Práticas de Gestão e Representações Sociais do Administrador: algum problema? Cadernos EBAPE, v.9, Edição Especial, Artigo 5, 2011.

CARRIERI, Alexandre de Pádua; SILVA, Alfredo Rodrigues Leite da; JUNQUILHO, Gelson Silva. O Fazer Estratégico na Gestão como Prática Social: Articulações entre Representações Sociais, Estratégias e Táticas Cotidianas nas Organizações. XXXII ENCONTRO DA ENANPAD. 2008.

CAVEDON, Neusa Rolita; FERRAZ, Deise Luiza da Silva. Representações Sociais e Estratégias de Pequenos Comércios. RAE Eletrônica, v. 4, Artigo 14, jan. jun. 2005.

CORRÊA, Alessandra Morgado Horta; GONTIJO, Maria Cecília Lemos; ASSIS, Lílian Bambirra de; CARRIERI, Alexandre de Pádua; MELO, Marlene Catarina de Oliveira Lopes. Soldadinhos-de-Chumbo e Bonecas: Representações Sociais do Masculino e Feminino em Jornais de Empresas. Revista de Administração Contemporânea (RAC), v.11. n.2, 2007.

CRAMER, Luciana; PAULA NETO, Alcielis; SILVA, Áurea Lucia. A Inserção do Feminino no Universo Masculino: Representações da Educação Superior. Organização \& Sociedade (O\&S). v.9, n. 24, 2002.

FANTIEL, Letícia Dias; CAVEDON, Neusa Rolita. A Cultura Organizacional do Restaurante Chalé da Praça XV em Porto Alegre: Espaços e Tempos Sendo Revelados. Revista de Administração Mackenzie, v. 11, n.1, 2010.

FARR, Robert. Representações Sociais: A teoria e sua História. Petrópolis: Vozes, 1995.

FLEIG, Daniel Gustavo; PEREIRA, Maria Cecília; GRYBOVSKI, Denise.. Reestruturação Produtiva e Subjetividade: Análise Interpretativa do Significado do Desemprego. Organização \& Sociedade (O\&S), v. 12, n. 33, 2005.

GUARESCHI, Pedrinho; JOVCHLOVITCH, Sandra. Textos em Representações Sociais. Petrópolis: Vozes, 2011.

KLEIN, H. K.; MYERS, M. D. A set of principles for conducting and evaluating interpretive field studies in information systems. MIS Quarterly, v.23, n.1, p. 67-94, 1999.

LEE, A.; BASKERVILLE, R. L. Generalizing generalizability in information systems research. Information Systems Research, v.14, n.3, p.221-243, 2003.

LESCURA, Carolina; BRITO, Mozar José de; BORGES, Alex Fernando; CAPELLE, Mônica Carvalho Alves. Representações Sociais sobre as Relações de Parentesco: Estudo de Caso em um Grupo Empresarial Familiar. Revista de Administração Contemporânea (RAC), v.16, n.1, p. 98-117, 2012. 
MARKOVÁ, Ivana. Dialogicidade e Representações Sociais. As Dinâmicas da Mente. Petrópolis: Vozes, 2006.

MELO, Marlene Catarina de Oliveira; CAPPELLE, Mônica Carvalho Alves; MAGESTE, Giselle de Souza; BRITO, Maria Jose Menezes. Representações Femininas na Mídia de Negócios Brasileira. Organização \& Sociedade (O\&S). v.11, n.31, 2004.

OLIVEN, Rubem George. De Olho no Dinheiro dos Estados Unidos. Revista de Estudos Históricos. v 1, n.27, 2001.

PATTON, Michael Quinn. Two Decades of Developments in Qualitative Inquiry: A Personal, Experiential Perspective. Qualitative Social Work. v.1, p.261-283, 2002.

PRASAD, Anshuman; PRASAD, Pushkala. The Coming Age of Interpretative Organizational Research. Organizational Research Methods. v.5, n.4, 2002.

SANDBERG, Jorgen. How Do We Justify Knowledge Produced Within Interpretative Approaches? Organizational Research Methods. v.8, n.1, p.41-68, 2005.

SOUZA, Washington José; SERAFIM, Lia Sales; DIAS, Thiago Ferreira. Representações Sociais do Papel de Gestores de Organizações Não-governamentais. Organização e Sociedade (O\&S). Salvador, v.17, n.53, p. 363-378, 2010.

TOMASELLI, Tatiana Renaux; OLTRAMARI, Leandro Castro. Possíveis Contribuições da Teoria das Representações Sociais às Finanças Comportamentais. Revista Eletrônica de Administração (REAd). Edição 56. Vol. 13. N². 2007

WAIANDT, Claudiani; DAVEL, Eduardo. Organizações, Representações e Sincretismo: a Experiência de uma Empresa Familiar que Enfrenta Mudanças e Sucessão de Gestão. Revista de Administração Contemporânea (RAC). v.12, n.2, 2008.

WALSHAM, Geoff. Doing interpretive research. European Journal of Information Systems, v.15, p.320-330, 2006. 